the TE of dSSc pupillary miosis was not different from controls. In NTE, a significantly different miosis between $1 \mathrm{SSc}$ and controls was induced by both SP concentrations $(\mathrm{p}<.001)$, while a significant difference between 1SSc and dSSc was found only when SP 10-3 M was used ( $p=.002)$. In $\mathrm{dSS} c$, the instillation of SP 10-3, but not of SP 10-5 M, induced in NTE a more intense miosis in respect to controls NTE $(p=.004)$. The comparison between TE and NTE was significantly different in controls $(\mathrm{p}<.001)$, but not in 1SSc and in dSSc.

Conclusion Our results show that ISSc is characterised by the involvement of neuroirideal junction. In fact, the irideal basal diameter is reduced, and SP induces a more intense miosis in respect both to dSSc and to HC. The lack of difference between TE and NTE could be due to a dysfunction of peripheral nervous system, more likely involving central control mechanisms.

\section{FRI0196 RELATIONSHIP BETWEEN BRONCHOALVEOLAR LAVAGE (BAL) AND HIGH RESOLUTION-CT (HRCT) FINDINGS IN SCLERODERMA LUNG DISEASE}

${ }^{1} R$ La Corte, ${ }^{1} D$ Santilli, ${ }^{1} R$ Tieghi, ${ }^{1} A$ Lo Monaco, ${ }^{2} F$ Ravenna, ${ }^{3} R$ Galeotti, ${ }^{4} N$ Prandini, ${ }^{1} \mathrm{~F}$ Trotta. ${ }^{1}$ Sez. Di Reumatologia; ${ }^{2}$ Ist. Di Pneumologia; ${ }^{3}$ st. Di Radiologia; ${ }^{4}$ Serv. Di Med. Nucleare, Università Di Ferrara, Ferrara, Italy

10.1136/annrheumdis-2001.277

\section{Background}

Objectives We assessed the presence of alveolitis by means of BAL and its correlations with HRCT findings in the diagnosis of systemic sclerosis (SSc)-related interstitial lung disease (SSc-ILD). Methods 43 nonsmoking patients (pts) with SSc, with a mean age of $54.62 \pm 2.08$ years (range $23-74$ ), underwent to: bronchoscopy with BAL according to the 1990 American Thoracic Society guidelines; ${ }^{1}$ lung HRCT, graded according to a scoring system proposed by Warrick et al.; ${ }^{2}$ and SSc-related antibodies testing.

Results Patients with alveolitis (A) and those without alveolitis (NA), divided according to BAL results, were comparable as to mean age and duration of disease, to the prevalence of diffuse or limited subset of disease, to mean values of skin score and to the results of examinations with respiratory function tests, diffusing capacity for carbon monoxide, and inhaled 99mTc-DTPA for the measure of alveolar clearance rate performed as part of the whole clinical assessment. BAL showed the presence of alveolitis in $18 / 43$ pts $(41.8 \%)$ with cell profiles so distributed: lymphocytic (L) in $5 / 18$ pts $(27.7 \%)$; eosinophilic (E) in 1/18 (5.5\%); pure neutrophilic $(\mathrm{N})$ in $5 / 18(27.7 \%)$ and a mixed pattern $(3 \mathrm{~N}$ $+\mathrm{L}, 3 \mathrm{~N}+\mathrm{E}, 1 \mathrm{~N}+\mathrm{L}+\mathrm{E})$ in $7 / 18(38.8 \%)$. Both "total HRCT" score $(14.3 \pm 1.2$ vs $9.2 \pm 1.2 ; \mathrm{p}=0.01)$ and "severity of disease" score $(8.8 \pm 0.8$ vs $6.0 \pm 0.8 ; \mathrm{p}=0.02)$ yelded significantly higher values in A pts compared with NA pts. Among HRCT abnormalities, only "honeycombing" (HC) was significantly more frequent in A pts $(\mathrm{p}=0.033)$; while the presence of "ground glass" (GG), "irregular pleural margins", "septal/subpleural lines" and "subpleural cysts" showed no differences between A and NA pts. Anti Scl-70 positivity was more prevalent in A pts $(\mathrm{p}=0.015)$ and, whether or not alveolitis was present, it correlated with higher "total HRCT" scores ( $\mathrm{p}=$ 0.039).

Conclusion Seemingly, GG cannot be unambiguously considered as the radiographic sign of alveolitis, since the latter is more prevalent in patients with $\mathrm{HC}$ which so, far from being the equivalent of a purely fibrotic outcome, could represent pathologic lung tissue that still retains some ongoing and potentially treatable inflammatory activity. Moreover, we confirm the role of anti Scl-70 as a negative prognostic marker associated with SSc-ILD.

\section{REFERENCES}

1 Am Rev Respir Dis. 1990;142:481

2 J Rheumatol. 1991;18:1520

\section{FRI0197 PROSTAGLANDIN E1 INFUSIONS AND PLASMA HOMOCYSTEINE IN SYSTEMIC SCLEROSIS}

${ }^{1} \mathrm{M}$ Massarotti, ${ }^{2} \mathrm{C}$ Maioli, ${ }^{2} \mathrm{~A}$ Bestetti, ${ }^{3} \mathrm{R}$ Coppola, ${ }^{4} \mathrm{~S}$ Leviti, ${ }^{1} \mathrm{~B}$ Marasini. ${ }^{1}$ Department of Medicine, Surgery and Dentistry, University of Milan; ${ }^{2}$ Institute of Radiological Sciences; ${ }^{3}$ Angelo Bianchi Bonomi Haemophilia and Thrombosis Centre, IRCCS Maggiore Hospital, Milan, Italy; ${ }^{4}$ Clinical Chemistry Laboratory

\subsection{6/annrheumdis-2001.278}

Background Although elevated plasma levels of homocysteine (Hcy) are considered a risk factor for vascular events, it is still uncertain if the lowering of Hcy by folate restores endothelial function.

Objectives We evaluated the relationship between Hcy and endothelial damage in systemic sclerosis (SSc), measuring plasma levels of von Willebrand factor ( $\mathrm{vWf}$ ), a well accepted marker of endothelial dysfunction, and Hcy, after treatment with PGE1, which has no known interferences with Hcy metabolism and whose long-term benefit is thought to be due to improvement of endothelial function.

Methods Sixty mcg PGE1 (alprostadil alpha-cyclodextrine) in $250 \mathrm{ml} 0.9 \%$ saline daily were infused daily for a 5 days-period (1st cycle), and after 1 and 2 months for 1 day-period thereafter (2nd and $3 \mathrm{rd}$ cycle, respectively) to $10 \mathrm{SSc}$ patients (2 with the diffuse, dSSc, 7 with the limited type, ISSc, 1 with SSc sine scleroderma. Hcy (immunoassay), vWf (ELISA) and folic acid (radioassay) were measured before each cycle.

Results Hcy was reduced vs baseline before the 2nd and 3rd cycle $(11.30 \pm 3.23$ and $12.16 \pm 4.86$ vs $14.46 \pm 5.31 \mathrm{mcM} / \mathrm{L}$, $\mathrm{p}<0.005$ and $\mathrm{p}=0.0616$, respectively; mean $\pm \mathrm{SD}$ ), with a percent decrease vs baseline significantly greater in dSSc vs $1 S S c$ $(66.0 \pm 9.7$ vs $83.1 \pm 7.0 \%, p<0.03$ and $64.2 \pm 14.5$ vs 88.4 $\pm 6.0 \%, \mathrm{p}<0.05,2 \mathrm{nd}$ and $3 \mathrm{rd}$ cycles). vWf was also reduced $(167 \pm 39$ and $156 \pm 27$ vs $183 \pm 12 \mathrm{U} / \mathrm{dl}, \mathrm{p}<0.05)$, with no differences between $1 S S c$ or dSSc. Folic acid did not change $(4.68 \pm 1.56,4.94 \pm 2.09$ and $4.54 \pm 1.71 \mathrm{ng} / \mathrm{ml})$. No relationship was observed between Hcy and vWf.

Conclusion These data are consistent with Hcy as a marker rather than a risk for endothelial damage. Further studies are however needed to evaluate the relatioship of Hcy and vWf plasma levels with endothelial function.

\section{FRI0198 THE ULTRASTRUCTURE OF THE MUSCLE COAT OF THE GASTRIC WALL IN A CASE OF SYSTEMIC SCLEROSIS (SSC)}

${ }^{1} \mathrm{~L}$ Ibba Manneschi, ${ }^{2} \mathrm{~A}$ Del Rosso, ${ }^{1} \mathrm{~A}$ Tani, ${ }^{1} \mathrm{~S}$ Pacini, ${ }^{3} \mathrm{P}$ Bechi, ${ }^{2} \mathrm{M}$ Matucci Cerinic. ${ }^{1}$ Department Anatomy, Histology and Forensic Medicine; ${ }^{2}$ Department Internal Medicine, Sect Rheumatol; ${ }^{3}$ Clinical Surgery, University of Florence, Florence, Italy

10.1136/annrheumdis-2001.279

Background In Systemic Sclerosis (SSc) the gastrointestinal (GI) involvement leads to hypomotility and dysphagia at esophageal 